\title{
Results of portal decompression in patients with primary biliary cirrhosis
}

\author{
R SPINSI,* G SMITH-LAING, $\dagger$ O EPSTEIN, AND S SHERLOCK \\ From the Academic Department of Medicine, Royal Free Hospital, London
}

SUMMARY Twenty-five patients with primary biliary cirrhosis undergoing portal decompression have been followed up for a mean of 51 months. Five patients with decompensated cirrhosis died postoperatively. Overall five year survival of $66 \%$ is comparable with that for other forms of cirrhosis but none of the long-term survivors, including three patients with a precirrhotic stage of primary biliary cirrhosis at the time of surgery, developed significant portal-systemic encephalopathy. The results suggest that portal decompression may be the therapy of choice for patients with wellcompensated primary biliary cirrhosis who suffer recurrent variceal haemorrhage.

Primary biliary cirrhosis may present with variceal haemorrhage due to portal hypertension. ${ }^{1}$ This was thought to represent a late stage of the disease and indicate a poor prognosis. ${ }^{2}$ However, Zeegan et al. ${ }^{1}$ demonstrated that portal hypertension could develop early and that only a quarter of their patients who presented with variceal haemorrhage showed nodular regeneration of the liver. A further report described five patients who survived long periods after shunt surgery and suggested that primary biliary cirrhosis was a good risk disease for such operations. ${ }^{3}$ Larger studies of the results of shunts in cirrhotic patients have included patients with primary biliary cirrhosis but have failed to show improved survival in this group. ${ }^{4}$

We have therefore studied post-shunt survival and the incidence of portal-systemic encephalopathy in patients with primary biliary cirrhosis. The influence of the histological stage of the disease on prognosis and the applicability of Child's method of assessing operative risk in such patients are discussed.

\section{Methods}

\section{PATIENTS}

Twenty-five patients with primary biliary cirrhosis had portal-systemic shunt surgery. Twenty-four patients were treated at the Royal Free Hospital

*Present address: L'Instituto de Patologia, Speciale Chiurgica II, dell' Universita, Pisa, Italy.

†Present address: Department of Gastroenterology, West Middlesex Hospital, Isleworth, Middlesex TW7 6AF.

Received for publication 9 January 1981 between 1960 and 1978. One patient had a portacaval shunt performed at another hospital. There were 22 females and three males (nos. 14, 21, 23). Patients were allocated to group A (excellent), B (moderate), and $C$ (poor) risk for surgery on the basis of serum bilirubin and albumin, the presence or absence of ascites or encephalopathy, and nutritional status as described by Child. ${ }^{5}$ The clinical details and Child's group of the patients is given in Table 1 . The diagnosis of primary biliary cirrhosis was made on the basis of clinical features, cholestatic liver function tests, and a diagnostic or compatible liver biopsy. ${ }^{6}$ Diagnosis was confirmed by the presence of antimitochondrial antibody in 21 patients. In four patients (nos. 9, 11, 13, 17) the test was not performed, although these patients fullfilled all the other criteria for the diagnosis of primary biliary cirrhosis. Liver biopsies were performed on all patients at the time of surgery; 20 patients had established cirrhosis and five patients were precirrhotic. All patients had had at least one variceal haemorrhage and varices were demonstrated by endoscopy and coeliac axis angiography or splenic venography. Hepatosplenomegaly was present in all patients. Nineteen patients (nos. 1-19) had end-toside portocaval anastomosis and the remainder a mesocaval shunt using a Dacron interposition graft. ${ }^{7}$ Six patients were shunted electively and the remainder during the same admission as their variceal haemorrhage. The shunts were performed by two surgeons, K E F Hobbs and P George.

Patients have been followed-up for a mean of 51 months (range one to 192 months). The presence of encephalopathy has been assessed clinically and 
Table 1 Clinical details of primary biliary cirrhosis patients with portal-systemic shunts

\begin{tabular}{|c|c|c|c|c|c|}
\hline Patient no. & Age at op. (yr) & Child & Histology & Survival (months) & Cause of death \\
\hline 1 & 53 & B & Precirrhotic & 50 & \\
\hline 2 & 51 & $\mathbf{A}$ & Cirrhotic & 55 & \\
\hline 3 & 58 & C & Cirrhotic & Post op. & Bleeding varices \\
\hline 4 & 51 & $\mathbf{A}$ & Precirrhotic & 52 & \\
\hline 5 & 42 & A & Precirrhotic & 184 & \\
\hline 6 & 51 & $\mathbf{B}$ & Cirrhotic & 34 & \\
\hline 7 & 49 & $\mathbf{C}$ & Cirrhotic & 14 & Bleeding varices \\
\hline 8 & 50 & $\mathbf{A}$ & Cirrhotic & 55 & \\
\hline 9 & 58 & $\mathbf{B}$ & Cirrhotic & 57 & \\
\hline 10 & 50 & $\mathbf{C}$ & Precirrhotic & 30 & Bleeding varices, occluded shunt \\
\hline 11 & 49 & $\mathbf{B}$ & Cirrhotic & 115 & \\
\hline 12 & 58 & $\mathbf{B}$ & Cirrhotic & 54 & \\
\hline 13 & 45 & $\mathbf{B}$ & Cirrhotic & 31 & \\
\hline 14 & 48 & $\mathbf{B}$ & Cirrhotic & 72 & Liver failure \\
\hline 15 & 65 & $\mathbf{C}$ & Precirrhotic & Post op. & Liver failure \\
\hline 16 & 41 & $\mathbf{B}$ & Cirrhotic & 63 & Hepatorenal failure \\
\hline 17 & 57 & $\mathbf{C}$ & Cirrhotic & 4 & Liver failure, occluded shunt \\
\hline 18 & 45 & $\mathbf{C}$ & Cirrhotic & Post op. & GI haemorrhage? source \\
\hline 20 & 57 & $\mathbf{C}$ & Cirrhotic & Post op. & Bleeding varices, occluded shunt \\
\hline 21 & 45 & $\mathbf{C}$ & Cirrhotic & Post op. & Bleeding gastric erosions \\
\hline 22 & 34 & $\mathbf{C}$ & Cirrhotic & 13 & Liver failure \\
\hline 23 & 63 & $\mathbf{B}$ & Cirrhotic & 13 & \\
\hline 24 & 48 & $\mathbf{B}$ & Cirrhotic & 45 & \\
\hline 25 & 52 & $\mathbf{C}$ & Cirrhotic & 6 & Liver failure \\
\hline
\end{tabular}

by the electroencephalogram and graded as absent if not detectable by either means, mild if present on electroencephalogram only, and severe if present clinically and on electroencephalogram.

Survival after operation has been calculated by the method of Armitage. ${ }^{8}$

\section{Results}

The overall five year survival was $66 \%$.

\section{POSTOPERATIVE DEATHS}

There were five deaths within 30 days of operation (Table 1). One patient died of hepatic failure and four patients from gastrointestinal haemorrhage. The source of bleeding was varices in two, gastric erosions in one, and undetermined in one. Shunt occlusion was suspected in both patients bleeding from varices and confirmed in one at necropsy. All the patients who died postoperatively had decompensated liver disease (Child's C) preoperatively. Interestingly, the liver biopsy in one of these patients showed a precirrhotic stage of primary biliary cirrhosis and the liver did not appear to be cirrtotic at surgery, suggesting that the histology did not reflect sampling error.

\section{LATE DEATHS}

There were seven late deaths (Table 1). Four patients died of liver failure at four, six, 13, and 72 months. Two patients died from variceal haemorrhage at 14 and 30 months. A blocked shunt was suspected in these patients and confirmed in one at necropsy. The final patient developed hepatorenal failure after a cholecystectomy and sphincteroplasty for gallstones.

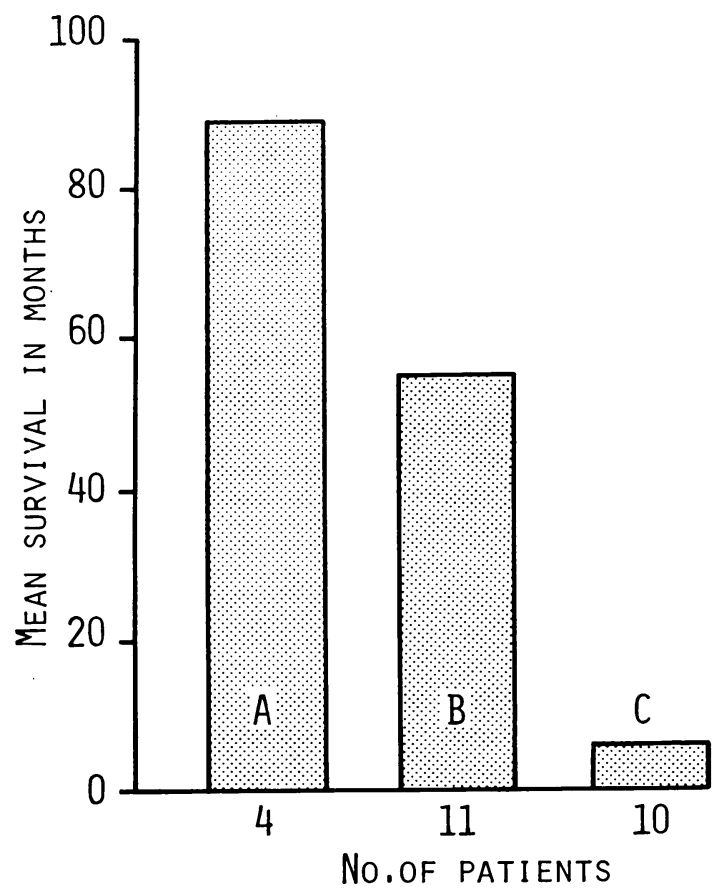

Figure The influence of Child's grading on survival after portal-systemic shunt surgery. 


\section{LATE SURVIVAL}

The one, five and 10 year survival rates (excluding postoperative deaths) were $90 \%, 74 \%$, and $38 \%$ respectively. Three patients with a precirrhotic stage of primary biliary cirrhosis have survived 50, 52, and 192 months respectively.

\section{INFLUENCE OF CHILD'S GRADING ON PROGNOSIS}

Mean survival for all patients was calculated for each Child's classification. Grade A patients survived for 90 months, grade B patients for 57 months, and grade $\mathrm{C}$ patients for six months (Figure).

\section{SHUNT OCCLUSION}

Six patients died from gastrointestinal haemorrhage and in four cases the source of haemorrhage was varices. Shunt occlusion was suspected in all cases and confirmed in two patients at necropsy. The two other patients were bleeding from gastric erosions as a terminal event. Patient 17 who died of liver failure and septicaemia at four months was found to have an occluded portocaval anastomosis at necropsy but there had been no recurrence of variceal haemorrhage. Shunt patency was assumed in the remaining patients in whom there were no further variceal haemorrhages.

\section{PEPTIC ULCERATION}

One patient with a previous duodenal ulcer had a recurrence of ulcer haemorrhage five years after the shunt. This was treated with cimetidine.

\section{POST-SHUNT ENCEPHALOPATHY}

All the patients who died in the postoperative period had severe encephalopathy from the time of operation till death. At one and four years none of the surviving patients had severe chronic encephalopathy (Table 2). At one year 7/18 (39\%) patients had EEG evidence of mild encephalopathy and, at four years, $3 / 11(27 \%)$ had mild encephalopathy. Dietary protein restriction was prescribed in eight patients and lactulose in nine patients.

\section{Discussion}

Primary biliary cirrhosis is a progressive fatal disease of unknown aetiology. The name primary biliary cirrhosis is a misnomer, as cirrhosis develops late in the disease. ${ }^{129}$ Portal hypertension is common and variceal haemorrhage has generally been associated with a poor prognosis. However, portal hypertension may develop early in the disease before cirrhosis has developed and is attributed to infiltration of the portal tracts with inflammatory cells. ${ }^{910}$ Portal hypertension is thought to be presinusoidal
Table 2 Pre-and post-shunt encephalopathy at one year and at four years

\begin{tabular}{|c|c|c|c|c|}
\hline \multirow{2}{*}{$\begin{array}{l}\text { Patient } \\
\text { no. }\end{array}$} & \multirow[t]{2}{*}{ Pre-shunt } & \multicolumn{2}{|c|}{ Follow-up $(y r)$} & \multirow[t]{2}{*}{ Treatment } \\
\hline & & 1 & 4 & \\
\hline 1 & Mild & Absent & Absent & \\
\hline 2 & Absent & Absent & Mild & \\
\hline 4 & Absent & Mild & Mild & $\mathbf{P R}+\mathbf{L}$ \\
\hline 5 & Absent & Absent & Absent & \\
\hline 6 & Absent & Absent & - & \\
\hline 7 & Absent & Absent & - & $\mathbf{L}$ \\
\hline 8 & Absent & Absent & Absent & $\mathbf{L}$ \\
\hline 9 & Absent & Mild & Mild & $\mathbf{P R}+\mathbf{L}$ \\
\hline 10 & Absent & Mild & - & \\
\hline 11 & Absent & Absent & Absent & PR \\
\hline 12 & Absent & Mild & 一 & PR \\
\hline 13 & Absent & Mild & - & $\mathbf{P R}$ \\
\hline 14 & Absent & Absent & Absent & \\
\hline 16 & Absent & Absent & Absent & $\mathbf{L}$ \\
\hline 19 & Absent & Absent & Absent & \\
\hline 22 & Mild & Mild & - & $\mathbf{P R}+\mathbf{L}$ \\
\hline 23 & Mild & Mild & - & $\mathbf{P R}+\mathbf{L}$ \\
\hline 24 & Absent & Absent & Absent & $\mathbf{L}$ \\
\hline
\end{tabular}

PR: Protein restriction. L: Lactulose.

at this stage, although wedged hepatic venous pressures may be raised in the absence of cirrhotic nodules. 11

Haemorrhage related to portal hypertension has for many years been treated by portal-systemic shunt surgery. However, large controlled trials have shown no improvement in survival of cirrhotic patients after shunt surgery ${ }^{12}{ }^{13}$ and the marked incidence of severe postoperative portal-systemic encephalopathy frequently negates the benefits of successful shunt surgery. ${ }^{1415}$ The results of shunt surgery in noncirrhotic portal hypertension are better as liver function is preserved and progression of disease is slow. ${ }^{16}$ There are few reports of shunt surgery in primary biliary cirrhosis where patients may have either cirrhotic or non-cirrhotic portal hypertension.

Twenty-three cases of primary biliary cirrhosis in a series of 251 patients with portal hypertension who underwent shunt surgery in a 19 year period had an overall five year survival of less than $50 \%{ }^{1}$ Kanel et $a .^{4}$ reported eight patients with a $35 \%$ five year survival after shunt and six patients with primary biliary cirrhosis among a large series of shunted cirrhotic patients reported from the Mayo Clinic had a five year survival of $60 \%{ }^{17}$ Hourigan et $a .^{18}$ reported four cases with 'biliary' cirrhosis undergoing elective portocaval anastomosis who had long survival without encephalopathy. Bauer et al. ${ }^{3}$ reported five cases of primary biliary cirrhosis undergoing shunt surgery in a six year period. These patients had a good survival despite an unfavourable Child's classification and Bauer attributed this to well-preserved liver function despite marked abnormalities in the liver function tests. Our series cannot be compared directly with these 
other series. However, a five year survival of $66 \%$ is similar to the five year survival of $65 \%$ reported from this hospital in patients with other types of cirrhosis undergoing elective portocaval anastomosis. ${ }^{18}$ The survival of our patients after shunting is far longer than that for 50 unshunted patients with primary biliary cirrhosis and established varices reported from this hospital who had a mean survival of 14.9 months. $^{2}$

Portal systemic encephalopathy is the major cause of morbidity in patients with portal-systemic shunts. About half the cirrhotic patients undergoing portocaval anastomosis develop chronic severe encephalopathy irrespective of the aetiology of the cirrhosis. ${ }^{17}$ This may be so severe as to prevent patients leading a normal life. The use of protein restriction, oralneomycin, and lactulose is usually successful in treating portal-systemic encephalopathy, although a small number of shunted patients fail to respond to these measures and are effectively incapacitated by their chronic encephalopathy. Severe chronic encephalopathy was not seen in any of our long-term survivors. Abnormalities of the electroencephalogram were seen in a small number of patients and this mild encephalopathy was easily controlled with protein restriction and lactulose. Four patients (Table 2) were started on protein restriction or lactulose in the absence of any evidence of encephalopathy as prophylaxis against its development.

There is no entirely satisfactory method of selecting patients for shunt surgery. Measurement of a number of haemodynamic variables has proved no more reliable than Child's functional classification. ${ }^{19}$ Doubts have been cast on the validity of Child's classification for assessing operative risk in patients with biliary cirrhosis. ${ }^{3}$ The results from this series suggests that Child's classification is valid. While bilirubin may be markedly raised with relative normality of the other liver function tests in patients with primary biliary cirrhosis, and thus adversely influences the Child's classification, hyperbilirubinaemia per se is associated with a poor prognosis in this disease. ${ }^{20}$

Five of our patients had a precirrhotic stage of primary biliary cirrhosis at the time of surgery. Even in these patients the functional grading has been reflected by survival. Three precirrhotic patients have survived for up to 16 years with no evidence of liver failure or encephalopathy. In these patients survival is probably determined by the progression of the liver disease. A survival of 16 years would be in keeping with the slow progression of the disease that occurs in some patients. ${ }^{21}$

Five year survival in patients with primary biliary cirrhosis and portal-systemic shunts is comparable with that for other forms of cirrhosis. However, shunt surgery removes the risk of bleeding without substituting portal-systemic encephalopathy. Child's functional classification offers a good guide to prognosis in such patients but the presence or absence of cirrhosis on liver biopsy should also be considered when selecting patients for shunt surgery. Other methods of treating variceal haemorrhage, such as endoscopic or transhepatic sclerosis of varices, may delay further bleeding but, as they do not decompress the portal system, recurrent haemorrhage from new varices is always a danger, although such measures should be considered for the patient with decompensated cirrhosis. Prevention of death from haemorrhage in such patients may allow long-term medical therapy with penicillamine, which appears to favourably influence the course of this disease. 2223

We thus conclude that portal decompression may be the treatment of choice in patients with primary biliary cirrhosis and portal hypertension who suffer repeated variceal haemorrhages.

\section{References}

${ }^{1}$ Zeegan R, Stansfield AG, Dawson AM, Hunt AH. Bleeding oesophageal varices as the presenting feature in primary biliary cirrhosis. Lancet $1969 ; 2$ : 9-13.

${ }^{2}$ Kew MC, Varma RR, Dos Santos HA, Scheuer PJ, Sherlock S. Portal hypertension in primary biliary cirrhosis. Gut 1971; 12 : 830-4.

${ }^{3}$ Bauer J, Gelernt I, Kreel I. Portal-systemic shunting in patients with primary biliary cirrhosis. Ann Surg 1976; 183: 324-8.

${ }^{4}$ Kanel G, Kaplan M, Zawacki J, Callow A. Survival in patients with postnecrotic cirrhosis and Laennec's cirrhosis undergoing therapeutic portocaval shunt. Gastroenterology 1977; 73: 679-83.

${ }^{5}$ Child CG. The liver and portal hypertension. Philadelphia: Saunders, 50: 1964.

${ }^{6}$ Scheuer PJ. Primary biliary cirrhosis. Proc $R$ Soc Med 1967; 60: 1257-60.

${ }^{7}$ Drapanas T. Interposition mesocaval shunt for treatment of portal hypertension. Ann Surg 1972; 176: 435-46.

${ }^{8}$ Armitage P. Statistical methods. Oxford: Blackwell, 408-14: 1971.

${ }^{9}$ Rubin E, Schaffner F, Popper H. Primary biliary cirrhosis. Chronic non-suppurative destructive cholangitis. Am J Pathol 1965; 46: 387-407.

${ }^{10}$ Sherlock S. Primary biliary cirrhosis (chronic intrahepatic obstructive jaundice). Gastroenterology 1959; 37: 574-86.

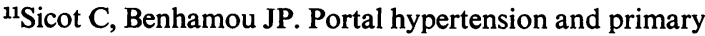
biliary cirrhosis. Proceedings of the fifth meeting of European association for the study of the liver. 1970: 25-6.

${ }^{12}$ Resnik RH, Chalmas TC, Ishihara AM, Garceau AJ, Callow AD, Schimmel EM, O'Hara. A controlled study of the prophylactic portocaval shunt. Ann Intern Med 1969; 70: 675-88. 
${ }^{13}$ Resnik RH, Iber FL, Ishihara AM, Chalmas TC, Zimmerman H. A controlled study of the therapeutic portocaval shunt. Gastroenterology 1974; 67: 843-57.

${ }^{14}$ Mutchnic MG, Lerner E, Conn HO. Portal-systemic encephalopathy and portocaval anastomosis: a prospective controlled investigation. Gastroenterology 1974; 66: 1005-12.

${ }^{15}$ Reynolds T, Donovan A, Mikkelsen W, Redeker A, Turrill F, Weiner J. Results of an 11 year randomised trial of end-to-side portocaval shunt in patients with alcoholic liver disease. (Abstract.) Gastroenterology 1978; 75 : 982.

${ }^{16}$ Zeegan R, Stansfield AG, Dawson AM, Hunt AH. Prolonged survival after portal decompression of patients with non-cirrhotic intrahepatic portal hypertension. Gut 1970; 11 : 610-7.

${ }^{17}$ Pliam M, Adson M, Foulk W. Conventional splenorenal shunts. Arch Surg 1975; 110 : 588-92.
${ }^{18}$ Hourigan K, Sherlock S, George P, Mindel S. Elective end-to-side portocaval shunt: results in 64 cases. $\mathrm{Br}$ Med J 1971 ; 4: 473-7.

${ }^{19}$ Reynolds T. Promises! Promises! Hemodynamics and portal-systemic shunt. $N$ Engl J Med 1974; 290: 1484-5. ${ }^{20}$ Shapiro JM, Smith H, Schaffner F. Serum bilirubin: a prognostic factor in primary biliary cirrhosis. Gut 1979; 20: $137-40$.

${ }^{21}$ Long RG, Scheuer PJ, Sherlock S. Presentation and course of asymptomatic primary biliary cirrhosis. Gastroenterology 1977; 72: 1204-7.

${ }^{22}$ Epstein O, De Villiers D, Potter BJ, Thomas HC, Sherlock S. Reduction of immune complexes and immunoglobulin induced by $D$-penicillamine in primary biliary cirrhosis. $N$ Engl J Med 1979; 300: $274-7$.

${ }^{23}$ Fleming R, Ludwig J, Dickson R. Asymptomatic primary biliary cirrhosis. Mayo Clin Proc 1978; 53: 587-93. 